\title{
Elements Making up the Profile of a Professional Teacher. A Qualitative and Quantitative Approach
}

\author{
Georgios Panagiotopoulos \\ University of Patras, \\ Megalou Alexandrou 1, Patras, 26334, Greece \\ Tel: 69-72-663-858 E-mail: pangiorgos@upatras.gr \\ Avramidou Sofia \\ Hellenic Open University \\ Tel: 69-38-659-710Ｅ-mail: std105306@ac.eap.gr \\ Zoe Karanikola (Corresponding Author) \\ University of Patras, \\ Megalou Alexandrou 1, Patras, 26334, Greece \\ Tel: 69-49-973-053E-mail:zoekaranikola3@gmail.com
}

Received: August 26, 2019 Accepted: September 25, 2019 Published: September 30, 2019

doi:10.5296/ijld.v9i3.15554 URL: https://doi.org/10.5296/ijld.v9i3. 15554

\begin{abstract}
This present study comes to investigate teachers' views on what constitutes teacher professionalism and whether these views are influenced by gender, age, educational level and teaching experience. Both a qualitative and a quantitative research approach were chosen. Three teachers were interviewed, whereas 83 teachers completed the questionnaire. According to the findings, professionalism is related to the teacher's knowledge, personal and interpersonal skills. In addition, a large proportion of participants associate professionalism with mastering basic communication skills, developing problem-solving strategies and utilizing appropriate teaching methods. Finally, emphasis is put on developing a culture of
\end{abstract}


collaboration between colleagues and between teachers and parents.

Keywords: professionalism, knowledge, skills, collaboration, qualitative and quantitative approach

\section{Theoretical Underpinning}

\subsection{The Concept of Professionalism}

A review of the relevant literature reveals that professionalism functions either as a mechanism for political and ideological control or as a value system (Crook, 2008; Evetts, 2003; Hilferty, 2008). Hoyle (1995) associates it with strategies aimed at upgrading authority, salary and working conditions, while Clarke and Newman (1997) consider that it shapes an organization's power patterns and interpersonal relationships. Drawing on ethics, Durkheim (1992) interprets it as a form of community that develops ethical characteristics because of the sense of belonging to a professional group.

In an attempt to understand better the notion of professionalism, researchers turn to a set of characteristics that distinguish the professions: the existence of a specialized knowledge base, the performance of any professional activity based on existing specialized knowledge, the existence of professional autonomy and integrity, sense of responsibility and rewards (Brante, 2011; Freidson, 2001; Yeom \& Ginsburg, 2007).

However, more recent interpretations of professionalism argue that it cannot be determined solely by objective criteria that define the employee's behavior and restrict them to the choice of professional practice. Rather, it emerges through a set of attitudes, behaviors, practices and standards, such as consistency, willingness, due diligence, creative thinking, credibility and the delimitation of personal and professional profile (Boyt, Lusch, \& Naylor, 2001).

\subsection{Concerns About the Issue of Professionalism in Education}

Professional knowledge, teacher's responsible attitude towards improving students, and teacher autonomy (Furlong et al., 2000; Leaton-Gray \& Whitty 2010) are key elements of educational professionalism. However, the degree of professional autonomy raises questions, given the centralized nature of the educational system (Freidson, 2001; Vanderstraeten, 2007). In addition, the professional knowledge of the teacher as well as the teaching process itself is considered not to be based on a rigorously established scientific basis (Lortie, 1975). Contrariwise, it seems to be the very nature of the educational task that involves a multitude of unforeseen situations, leading to the operation of a different form of knowledge based on the personal experience of the teacher.

In addition, the answers to the problems of the teaching practice are not coming of a specific professional knowledge base, but depend greatly on the background of the learning potential. Consequently, they require the development of individual judgment as a product of primarily intuition that is born and evolves through the experience gained by teachers during their service (Whitty, 2008).

Phelps (2006) additionally refers to the enhancement of professionalism when teachers use the 
highest standards as criteria for evaluating their actions and attitudes, whereas equally interesting is the approach of Jamous and Pelloile (1970) who distinguish professionalism related to flexibility, consistency and responsibility from high professionalism related to expertise and non-transferable traits such as individual intelligence, talent or charisma.

Central to the demonstration of professionalism in education is the teacher's ability to enhance students' learning behavior, the learning process itself (Ifanti \& Fotopoulopou, 2011) but also to collaborate with other persons and entities (Gritzios, 2006). Collaborative culture development theory was first described by Alfonso and Goldsberry (1982) who support the development of professional communities through collaboration, as teachers can act as a professional by creating favorable conditions for improving the educational work by exploiting diffusion, information and innovation, workload sharing and enhancing personal ethics. In fact, this trend was later described as "new professionalism" mainly because it contradicted the traditional authority and autonomy of the teacher at that time (Hargreaves, 1994).

Lawrence Stenhouse (a.c. Day, 2003: 31), referring to professionalism, refers to the possibility of autonomous professional development through systematic individual study, the study of the work of other teachers, and the questioning and testing of various ideas through in-class research processes.

There is therefore an interdependence between the concepts of professionalism and professional development, as professionalism seems to be linked and reinforced by it. Indeed, professional development itself can be understood through its contribution to enhancing prestige as well as improving the knowledge, skills and practices of each profession (Evans, 2008; Kirkwood \& Christie, 2006).

In the same context, participation in teacher lifelong learning and training processes is an important tool towards this direction. Helsby and McCulloch (1996) refer to the range of teachers' tasks that aim to improve their knowledge for the benefit of service providers, thereby gaining the recognition and consequent authority in the wider social - professional context environment.

Hargreaves and Goodson (1996) also attempt to deepen the interpretation of professionalism by referring to a process related to the ways in which teachers seek to enhance the quality and character of the educational process. In particular, there is a reference to the greater responsibility of teachers in defining the nature and content of their work. At this point, Hilferty (2008) focuses on a slightly different term, that of in-service professionalism, which refers to trying to influence and improve the characteristics and character of their work and may concern teachers' involvement in designing educational policy (curricula, etc.), recognizing the specialization of their subject and finally seeking to upgrade their professional standing.

\section{Methodology of Research}

\subsection{Research Objective - Research Tools}

The purpose of the present study is to investigate teachers' views on what constitutes a teacher's 
professionalism and whether these views differ according to gender, age, educational level and teaching experience. On the basis of this aim, the quantitative and qualitative research approach were chosen. This option helps to compensate for the weaknesses of each method, to give the best possible results and to enhance the interpretation (Robson, 2007).

The sample of the quantitative method consisted of a total of 83 teachers of different specialties working in primary schools, whereas the convenient sampling was selected mainly due to the easy access to the sample (Creswell, 2016). The sample of the qualitative approach consisted of three individuals who accepted to be interviewed.

The semi-structured interview guide that was created followed four central axes structured according to the research objective, literature review, definitions and research questions. In the present study, however, the results of the two first axes will be presented. Specifically, at the beginning of the interview (1st axis) questions were asked to make the profile of the interviewee. Identified demographics (gender, age, teaching experience, educational level, experience of in-service training) were identified through defined questions. The second axis explored the views around the elements that make up the image of a professional teacher.

Attention was paid to the structure and the sequence of the questions, to the conditions and technical support of the interview, to the time and place of the interview in order to ensure reliability (Robson, 2010).

Regarding the questionnaire, it was selected as a methodological tool for the collection of the quantitative data. Questionnaire is a very popular tool because of the widespread use of the internet, which makes it easy to gather the required data fast (Creswell, 2016; Robson, 2010). Its construction was based on the questions developed in the interview, on the bibliographic review and the research questions. In addition, closed-ended questions were selected for statistical analysis, providing distinct, comparable and classified results while being easily and quickly answered by participants (Cohen \& Manion, 1994).

The questionnaire consists of four research areas, with the first (A) including demographic data (four questions) and the remaining three $(\mathrm{B}, \mathrm{C}, \mathrm{D})$ corresponding to the three research questions that were studied. There is a total of 63 closed-ended questions. However, in the present study, the findings from the first two research areas will be presented ( 25 questions).

Regarding its reliability, it is ensured when the values of a tool are stable and consistent each time a researcher delivers it (Creswell, 2016). Specifically, the questionnaire was given twice in a portion of the same sample over a sufficient period of time to check the relevance of the answers given. Price control has resulted in sufficient consistency, which ensures the reliability of the tool.

\subsection{Data Analysis}

The analysis of the qualitative data followed a series of procedures related to their coding, categorization and analysis. The interviews were first transcribed. Subsequently, the researcher identified the answers to the queries and coded the material with key ideas and keywords. It is important to note that during this phase a significant portion of the participants' responses were 


\section{Al Macrothink Institute ${ }^{\mathrm{TM}}$}

not included in the analysis and then in the final presentation. The process of categorization led to the subsequent construction of broader categories - themes that emerged from the merging of codes into repetitive patterns. These data were recorded and constituted the material for continuing the process. The final phase was the presentation of the results presenting the broader categories - themes as well as extracts from the interviews documenting them.

Regarding the statistical procedure, initially the data was analyzed for the purposes of quoting and coding them into a reference list. Then the SPSS statistical program was used for the input of the data in order to carry out all the necessary variables measurements and comparisons. Specifically, descriptive statistic was used in order to analyze variables individually and to describe data trends (mean, percentage) with respect to each of the research questions raised. In addition, inductive statistics ( $\chi 2$ analysis) were used to analyze and compare variables at the same time (Creswell, 2016). The results were presented in the form of grouped bars and pies.

As far as the reliability of the scale, the Cronbach's Alpha, the statistical index of internal consistency, as a whole was 0.81 , which represents satisfactory quality of the measurement.

\subsection{Qualitative Research Results}

The three teachers (females) who participated in the interview received E1, E2 and E3 aliases to ensure their anonymity. The first woman has 22 years teaching experience, she is a graduate of English Literature University, while she has participated 15-20 times in in-school training. The second participant has 20 years of teaching experience, she is a graduate of the Pedagogic Department of Primary Education, with a postgraduate degree, whereas she has participated more than 15 times in in-school training and once in a distance education course. The third participant has 13 years of teaching experience, she is also a graduate of the Pedagogic Department of Primary Education, with a postgraduate degree, while she has participated about 10 times in in-school training programs and twice in distance education courses.

Regarding the question about the key elements that make up a professional teacher's image, the research results are presented in the table below (Table 1). 


\section{Macrothink}

Table 1. The research results on the components of professionalism

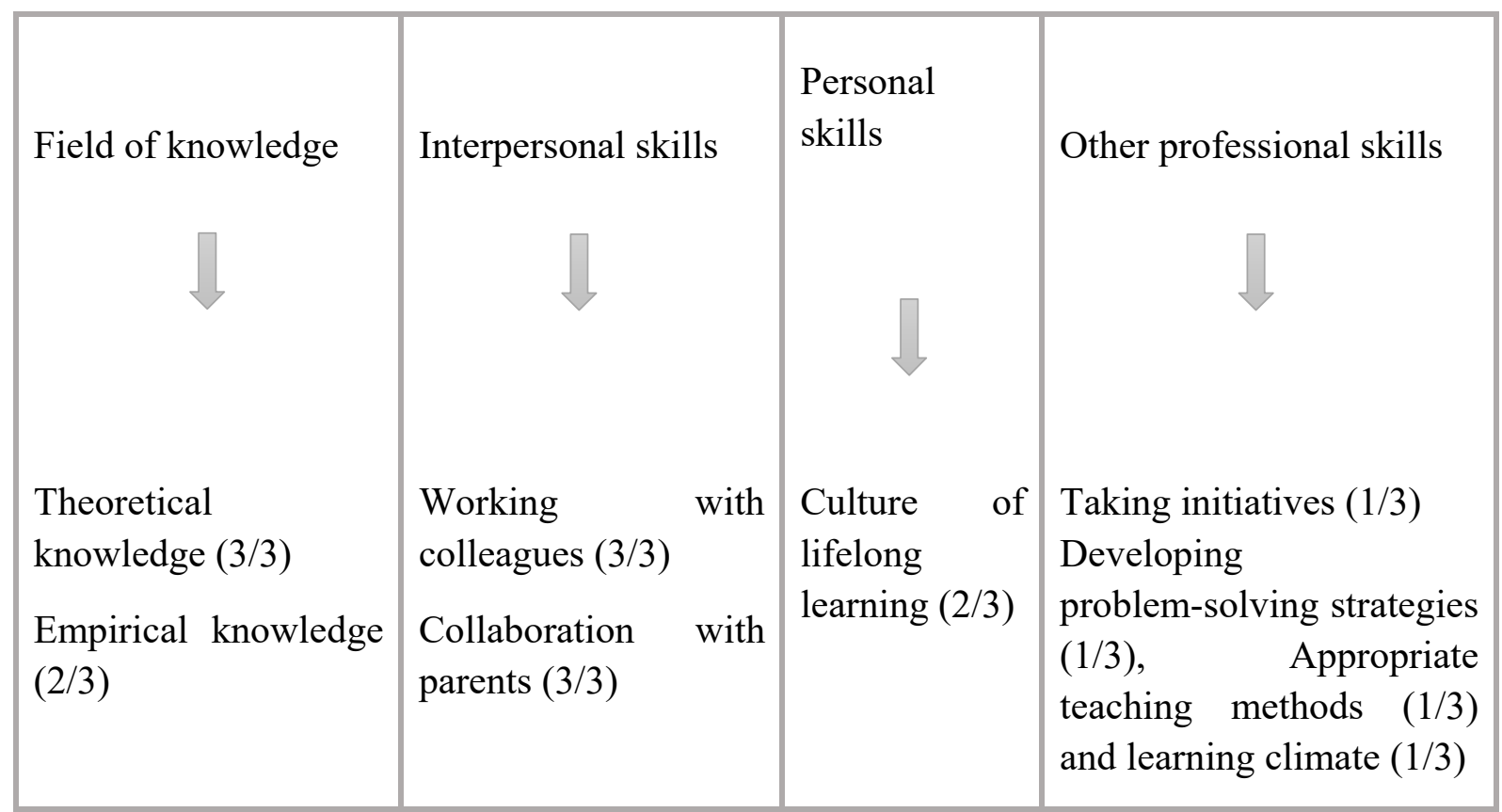

The analysis of the data shows that a key set of data that constitutes professionalism according to interviewers relates to the cognitive domain. According to their statements, both the theoretical knowledge acquired during studies (3/3) and the empirical knowledge acquired in the workplace are regarded as being important factors of professionalism.

A similar consensus seems to exist in the case of the teacher's interpersonal skills regarding their cooperation with colleagues (3/3) and students' parents (3/3). Typically mentioned:

"... to say that working with parents is an extremely important part of our job. Perhaps the most important. It is a prerequisite for me to be able to work effectively with my students."

"The way you work with others is also very important... interacting with colleagues. It is essential to be able to work within a co-operative framework and not to act individually.... It is also important to communicate and cooperate with parents as well."

The link between professionalism and the teacher's personal skill in having a broader lifelong learning culture was also identified (2/3), while in addition, reference was made to other professional skills of the teacher. Some referred to the teacher-student relationship and identified elements of professionalism in the development of appropriate teaching methods for students (1/3) as well as in the creation of an appropriate learning climate for them (1/3).

Finally, the ability to take initiatives (1/3) and the development of problem-solving strategies in the school environment (1/3) were also referred as very important aspects of teacher professionalism.

\subsection{Quantitative Research Results}

Women constituted $79.5 \%(\mathrm{~N}=66)$ of the sample and men $20.5 \%(\mathrm{~N}=17) .50 .6 \%$ have a 


\section{N Macrothink}

teaching experience of 5 to 15 years $(\mathrm{N}=42), 25.3 \%$ experience of $16-25$ years $(\mathrm{N}=21)$, $13.3 \%$ have less than 5 years $(\mathrm{N}=11)$ and $10.8 \%$ have over 26 years $(\mathrm{N}=9)$. In terms of education level, $50.6 \%(\mathrm{~N}=42)$ are graduates of the Pedagogical Department, $28.9 \%(\mathrm{~N}=24)$ are graduates of other specialties and $8.4 \%(\mathrm{~N}=7)$ are graduates of the Pedagogical Academy. In addition, it was observed that $36.1 \%(\mathrm{~N}=30)$ have a postgraduate degree, $10.8 \%(\mathrm{~N}=9)$ hold a second degree, while only $1.2 \%(\mathrm{~N}=1)$ hold a doctorate.

In order to investigate the research question concerning the components that make up the image of a professional teacher, the degree of importance that teachers attach to specific skills and characteristics related to the teacher's professionalism was studied.

Professionalism was initially studied in relation to the teacher's field of knowledge. Based on the data analysis, a significant relation (enough) was found with the possession of the basic scientific theoretical framework $(42.2 \%, \mathrm{M}=3.7)$, while the case of knowledge derived from personal experience $(44.6 \%, \mathrm{M}=4.11)$ was similarly significant.

Then the relationship of professionalism with specific professional skills was explored. The range of responses was mainly found between the "very" and "enough" options for the specific skills studied. Mastery of basic communication skills (verbal and written expression) (63.9\%, $\mathrm{M}=4.34)$, development of problem-solving strategies $(51.8 \%, \mathrm{M}=4.46)$, utilization of appropriate teaching methods $(66.3 \%, \mathrm{M}=4.66)$ were identified as very important skills.

Initiatives $(47 \%, \mathrm{M}=4.31)$ and decision-making $(42.2 \%, \mathrm{M}=4.17)$ proved to be important enough elements of professionalism. Similarly significant was the ability to create an appropriate learning climate in the classroom $(66.3 \%, \mathrm{M}=4.34)$ and to evaluate information $(59 \%, M=4.19)$.

Regarding Information and Communication Technologies (ICT) and their relation to professionalism, teachers rated ICT skills as important enough $(47 \%, M=4)$, while most of the participants rated the integration of ICT into every subject as important enough as well $(57.8 \%$, $\mathrm{M}=3.58)$.

Professionalism was also explored through the interpersonal skills of the teacher. According to the findings, a large proportion of the sample indicated that developing a culture of collaboration with colleagues is a very important aspect of educational professionalism $(63.1 \%$, $\mathrm{M}=4.64)$, whereas the development of a collaborative culture with parents $(65.5 \%, \mathrm{M}=4.34)$ and the wider involvement of teachers in teamwork $(65.1 \%, \mathrm{M}=4.35)$ were also found to be significant enough.

Options varied in the degree of importance of conflict management and conflict resolution, since a part of the sample rated this factor as significant $(66.3 \%$ overall for very and enough options), while $33.7 \%$ of the participants placed it in the 3 rd tier of the scale in the "Moderate" option $(\mathrm{M}=3.9)$.

Another area that was explored was that of personal skills. The findings highlighted the existence of a lifelong learning culture $(73.5 \%, \mathrm{M}=4.73)$ and the consistency and responsibility of the teacher $(72.3 \%, \mathrm{M}=4.72)$ as very important elements of professionalism. 


\section{Macrothink Institute ${ }^{\text {TM }}$}

Equally important is the distinction between personal and professional profile $(63.9 \%, \mathrm{M}=$ 4.64). It should also be noted that the element of the teacher's management of emotions in the workplace turned out to be important enough.

The elements of teacher's creativity and flexibility were finally explored. Based on the findings, about half of the sample rated flexibility $(49.4 \%, \mathrm{M}=4.05)$ as important enough, while creativity was rated as moderate $(62.7 \%, \mathrm{M}=3.16)$.

\subsection{Findings from the Correlation of Variables}

Statistical significance is found between the view of developing problem-solving strategies and the gender of the female $(\mathrm{p}<0.05)$. Additional statistical significance is found among teachers who are mainly in the "5 to 15 years" category and the views related to the association of professionalism with knowledge based on personal experiences, to communication skills and initiatives $(\mathrm{p}<0.05)$ (Table 2$)$.

Table 2. Relationship between gender and views on the components of professionalism

\begin{tabular}{lll}
\hline Gender - Viewpoint & $\chi^{2}$ & $\mathbf{p}$ \\
\hline Developing problem-solving strategies & 12.005 & .002 \\
Teaching experience - Viewpoint & $\chi^{2}$ & $\mathbf{p}$ \\
Knowledge based on personal experiences & 19.534 & .021 \\
Basic communication skills (written and spoken) & 13.176 & .040 \\
Taking initiatives & 12.137 & .049 \\
\hline
\end{tabular}

\section{Discussion on the Results}

According to the findings emerging from the qualitative and quantitative research, it is obvious that there is a very important link between professionalism and the possession of specialized theoretical knowledge. The existence of an adequate theoretical framework is also highlighted through the literature review with Tichenor and Tichenor (2005) and Okas, Schaaf and Krull (2014) focusing on the importance of having basic pedagogical knowledge. This is a finding that reveals that teachers view professional knowledge as an integral part of their professionalism, possibly because they perceive it as necessary in order to meet the requirements of their work.

Relevance seems to be given to the knowledge that comes from practical action in their professional field. This position is also confirmed by the frequent reference of teachers to their professional experience, which may be justified by the value they attach to everyday classroom practice and the knowledge gained through it as a product of experiential learning. This is a view expressed by Whitty (2008) who also refers to the utility of the teachers' intuition in managing everyday situations as a result of the experience gained during their service. 


\section{Macrothink

A large number of participants are also identified to associate professionalism with mastering basic communication skills, developing problem-solving strategies and utilizing appropriate teaching methods. Indeed, Ifanti and Fotopoulopou (2011) characterize teaching methods as essential tools for effective student learning. However, one important part of the sample observes that decision-making is not an important aspect of professionalism. This could possibly happen because teachers do not fully enjoy the status of autonomy and they are often under state organizational control (Freidson, 2001; Vanderstraeten, 2007).

Perhaps the most important aspect of teacher professionalism is the development of a culture of cooperation, a finding common with those of Tichenor and Tichenor (2005), Ifanti and Fotopoulopou (2011) and Okas, Schaaf and Krull (2014). This view reveals the professional maturity of teachers who are able to recognize the multiple benefits provided by collaboration. As Hargreaves (1994) points out, teachers can expand their educational palette with additional information and enhance their ethics through appropriate collaboration conditions. In particular, cooperation with parents tends to become increasingly accepted as its complementary role in the educational process is more and more recognized (Whitty, 2008).

The development of a broader lifelong learning culture of the teacher is also a factor highlighted both in this research and other similar (Ifanti \& Fotopoulopou, 2011; Okas, Schaaf \& Krul, 2014). Finally, the importance of consistency and responsibility as additional important skills related to teachers' professional behavior is also identified by Jamous and Pelloile (1970).

Based on the foregoing, the connection of professionalism with the development and acquisition of appropriate skills appears. These skills are also advocated by the OECD (2017), as evidenced by the content analysis of the text "OECD skills outlook 2017: Skills and global value chains" (Panagiotopoulos \& Karanikola, 2018). This text proposes information and technology skills, management and communication skills, self - organizing skills. In addition, reference is also made to general cognitive skills, which partly reflect the ability to learn, and benefit from training.

Given that these findings cannot be generalized, researches, both qualitative and quantitative, with larger samples should be conducted in the future. The case of teacher autonomy can be explored to a greater extent, especially in the light of the factors that may influence and shape teachers' views on this issue.

\section{References}

Alfonso, R., \& Goldsberry, L. (1982). Colleagueship in supervision. In T. Sergiovanni (Ed.), Supervision of teaching (p. 99). VA: Association for Supervision and Curriculum Development.

Boyt, T. E., Lusch, R. F., \& Naylor, G. (2001). The Role of Professionalism in Determining Job Satisfaction in Professional Services: A Study of Marketing Researchers. Journal of Service Research, 3(4), 321-330. https://doi.org/10.1177/109467050134005

Brante, T. (2011). Professions as Science-based Occupations. Professions and 
Professionalism, 1(1), 4-20. Retrieved from: https://doi.org/10.7577/pp.v1i1.147

Clarke, J., \& Newman, J. (1997). The managerial state. London: Sage Publications.

Cohen, L., \& Manion, L. (1994). Research methods in education (4th ed.). London: Routledge.

Creswell, J.W. (2016). Research in education: Design, conduct and evaluation of quantitative and qualitative Research. Athens: Ion.

Crook, D. (2008). Some historical perspectives on professionalism. In B. Conningham (Ed.), Exploring professionalism. Institute of Education: University of London.

Day, C. (2003). The evolution of Teachers. Athens: Typothyto - Dardanos.

Durkheim, E. (1992). Professional ethics and civil morals. London: Routledge.

Evans, L. (2008). Professionalism, Professionality and the Development of Education Professionals. British Journal of Educational Studies, 56(1), 20-38. https://doi.org/10.1111/j.1467-8527.2007.00392.x

Evetts, J. (2003). The Sociological Analysis of Professionalism. Occupational Change in the Modern World. International Sociology, 18(2), 395-415. https://doi.org/10.1177/0268580903018002005

Freidson, E. (2001). Professionalism, The third logic: On the practice of knowledge. Chicago: University of Chicago Press.

Furlong, J., Barton, L., Miles, S., Whiting, C., \& Whitty, G. (2000). Teacher education in transition: Reforming professionalism? Buckingham: Open University Press.

Gritzios, B. (2006). The New Professionalism Teacher Movement. Scientific Step, 6(1), 154-156.

Hargreaves, A. (1994). Changing teachers, changing times. Teachers'work and culture in the postmodern age. London: Cassell.

Hargreaves, A., \& Goodson, I. (1996). Teachers' professional lives: Aspirations and actualities. In I.F. Goodson and A. Hargreaves (Eds.), Teachers' professional lives. London: Falmer Press.

Helsby, G. (1996). Defining and Developing Professionalism in English Secondary Schools. Journal of Education for Teaching, 22(2), 135-148. https://doi.org/10.1080/02607479620313

Helsby, G., \& McCulloch, G. (1996). Teacher professionalism and curriculum control. In I. Goodson and A. Hargreaves (Eds.), Teachers 'professional lives. London: Falmer.

Hilferty, F. (2008). Theorizing teacher professionalism as an enacted discourse of power. British Journal of Sociology of Education, 29(2), 161-173. https://doi.org/10.1080/01425690701837521

Hoyle, E., (1995). Changing conceptions of a profession. In H. Busher and R. Saran (Eds.), 
Managing teachers as professionals in schools. London: Kogan Page.

Ifanti, A. A., \& Fotopoulou, V. S. (2011). Teachers' Perceptions of Professionalism and Professional Development: A Case Study in Greece. World Journal of Education, 1(1), 40-51. https://doi.org/10.5430/wje.v1n1p40

Jamous, H., \& Pelloile, B. (1970). Changes in the French university-hospital system. In A. J. Jackson (Ed.), Professions and professionalization (p.p. 111-152). Cambridge: Cambridge University Press.

Kirkwood, M., \& Christie, D. (2006). The role of teacher research in continuing professional development. British Journal of Educational Studies, 54(4), 429-448. https://doi.org/10.1111/j.1467-8527.2006.00355.x

Leaton-Gray, S., \& Whitty, G. (2010). Social Trajectories or Disrupted Identities? Changing and Competing Models of Teacher Professionalism Under New Labor. Journal of Education, 40 (1), 5-23. https://doi.org/10.1080/03057640903567005

Lortie, D. C. (1975). Schoolteacher: A sociological study. Chicago: University of Chicago Press.

OECD. (2017). OECD Skills outlook 2017: Skills and global value chains. Paris: OECD Publishing. Retrieved from https://doi.org/10.1787/9789264273351-en

Okas, A., van der Schaaf, M., \& Krull, E. (2014). Novice and experienced teachers' views of professionalism. Trames, 4, 327-344. https://doi.org/10.3176/tr.2014.4.02

Panagiotopoulos, G., \& Karanikola, Z. (2018). Occupational and Professional Development: OECD Policy Analysis on Skills. International Journal of Developing and Emerging Economies, 6(4), 1-10.

Phelps, P. H. (2006). The Three Rs of Professionalism. Kappa Delta Pi Record. https://doi.org/10.1080/00228958.2006.10516436

Robson, C. (2007). How to do a research project: A guide for undergraduate students. Oxford, UK: Blackwell Publishing.

Tichenor, M. S., \& Tichenor, J. M. (2005). Understanding teachers' perspectives on professionalism. The Professional Educator, 27(1), 89-95.

Vanderstraeten, R. (2007). Professions in organizations, professional work in education. British Journal of Sociology of Education, 28(5), 621-635. https://doi.org/10.1080/01425690701505516

Whitty, G. (2008). Teacher professionalism in new times. Journal of In-service Education, 26(2), 281-295. https://doi.org/10.1080/13674580000200121

Yeom, M., \& Ginsburg, M. (2007). Professionalism and the reform of teachers and teacher education in the Republic of Korea and the United States of America. Asia Pacific Education Review, 8(2), 298-310. https://doi.org/10.1007/BF03029264 


\section{Macrothink}

International Journal of Learning and Development

ISSN 2164-4063 2019, Vol. 9, No. 3

\section{Copyright Disclaimer}

Copyright for this article is retained by the author(s), with first publication rights granted to the journal.

This is an open-access article distributed under the terms and conditions of the Creative Commons Attribution license (http://creativecommons.org/licenses/by/4.0/). 